\title{
Osteoporosis in treated adult coeliac disease
}

\author{
X A McFarlane, A K Bhalla, D E Reeves, L M Morgan, D A F Robertson
}

\begin{abstract}
Forty five women and 10 men with coeliac disease diagnosed in adult life, who were already on a gluten free diet, had serial bone mineral density measurements at the lumbar spine and femoral neck over 12 months. Osteoporosis, defined as a bone mineral density (BMD) $\leqslant 2$ SD below the normal peak bone mass was found in $\mathbf{5 0 \%}$ of male and $47 \%$ of female coeliac patients. Patients with a BMD $\leqslant 2$ SD below age and sex matched normal subjects, had a significantly lower body mass index $\left(21 \cdot 3 \mathrm{~kg} \cdot \mathrm{m}^{-2}\right.$ compared with $25 \cdot 2$ kg.m ${ }^{-2}, p<0.02$ Wilcoxon rank sum test) and lower average daily calcium intake (860 mg/day compared with $1054 \mathrm{mg} /$ day, p $<0.05$ Wilcoxon rank sum test) than patients with normal bone mineral density. In postmenopausal women with coeliac disease there was a strong correlation between the age at menopause and $B M D$ at both the lumbar spine $(r=0.681$, $\mathbf{p}<0 \cdot 01$, Spearman's rank correlation) and femoral neck $(r=0.632, p<0.01)$. No overall loss of bone was shown over the 12 months of follow up, and relative to the reference population there was a significant improvement in BMD at the lumbar spine in women $(p<0.025$, paired $t$ test) and at the femoral neck in men $(p<0.05$, paired $t$ test). There was a significant negative correlation between the annual percentage change in $B M D$ at the lumbar spine and the duration of gluten free diet $(r=-0.429, p<0.01$, Spearman's rank correlation), with the largest gain in BMD in patients with most recently diagnosed coeliac disease. Osteoporosis was shown in $47 \%$ of patients with treated adult coeliac disease. Recognised risk factors for osteoporosis in the general population including low body mass index, dietary calcium intake, and early menopause are particularly important in coeliac disease. Treatment of coeliac disease with a gluten free diet probably protects against further bone loss, and in the early stages is associated with a gain in bone mineral density. (Gut 1995; 36: 710-714)
\end{abstract}

Keywords: coeliac disease, osteoporosis, gluten free diet.

Osteomalacia, bone pain, pathological fractures, and osteoporosis can occur as presenting features of coeliac disease, ${ }^{1-6}$ particularly where there is florid malabsorption leading to vitamin $\mathrm{D}$ deficiency. Patients with coeliac disease now present more often in adult life with mild nutritional deficiencies such as iron or folic acid deficiency, ${ }^{78}$ and recent reports suggest that reduced bone mineral density is common at presentation. ${ }^{910}$ We therefore studied the prevalence of osteoporosis in asymptomatic adults with treated coeliac disease, and utilised serial bone mineral density measurements to detect any change in bone mineral density over 12 months.

\section{Subjects}

Fifty five patients (45 women and 10 men) with coeliac disease diagnosed in adult life $(\geqslant 18$ years old at the time of diagnosis) and already established on a gluten free diet were recruited to the study from the gastroenterology outpatients department at the Royal United Hospital, Bath between 24 September 1991 and 21 October 1992. Coeliac disease was defined as small intestinal malabsorption associated with the characteristic small intestinal mucosal lesion together with clinical and histological improvement on a gluten free diet. ${ }^{11}$

The average age of the men was 50.2 years (range 27.0-65.0 years) and that of the women was 51.3 years (range 33.6-69.1 years). With regard to the women, the average age at menarche was 14 years (range 10-20 years; five patients had menarche at age 16 years or older). Five women (no overlap with the delayed menarche group) had a history of an episode of premenopausal amenorrhoea of at least six months. Sixteen women were premenopausal, 11 were perimenopausal, and 18 were postmenopausal (average age at menopause was 46.3 years, range 34 to 57 years, eight patients had had the menopause at age less than 45 years).

Seven patients had been previously treated with oral vitamin $\mathrm{D}$ preparations, six had been on glucocorticoids in the past, and five of the women were either on, or had previously been on, hormone replacement therapy for more than 12 months. Fourteen patients (two men) had a history of a serious fracture (rib, clavicle, ankle, forearm, sternum, scaphoid).

The average weight of the women was $61.7 \mathrm{~kg}$ (range $35-92.7 \mathrm{~kg}$ ) and that of the men was $74.5 \mathrm{~kg}$ (range $55-97 \mathrm{~kg}$ ). The average height of the women was $1.62 \mathrm{~m}$ (range $1.40-1.75 \mathrm{~m})$ and that of the men was $1.74 \mathrm{~m}$ (range 1.60-1.86 m). The mean times spent on a gluten free diet were 4.25 years (range $0 \cdot 4-10$ years) in men and $9 \cdot 2$ years (range $0 \cdot 3-40$ years) in women.

\section{Methods}

A dietary assessment was performed, based on a 10 day weighed record ${ }^{12}$ of all food consumed, and the dietary intakes of calcium, 


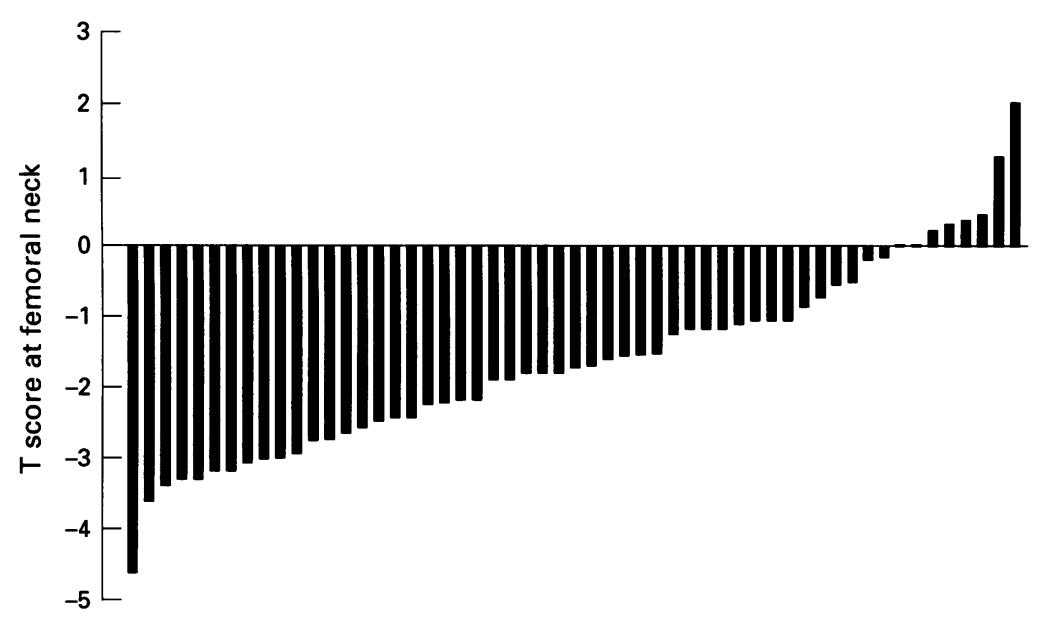

Figure 1: Ranked T scores (number of SDs by which individual patients bone mineral density differs from peak bone mass of normal sex matched adults) in 55 patients with adult coeliac disease. isolated reduction of $\mathrm{T}$ score as osteopaenia, and require in addition, the presence of fragility fracture to diagnose osteoporosis. ${ }^{17} 18$

The $\mathrm{Z}$ score provides an index of the relative risk of fracture compared with that of an individual with $\mathrm{Z}$ score of 0 . A bone mineral density $Z$ score of -1 at the femoral neck suggests a 2.6 fold increased risk of fracture over the patient's lifetime, and a $\mathrm{Z}$ score of -2 implies a $5 \cdot 2$ fold increased risk of fracture. ${ }^{19}$ The $\mathrm{Z}$ score is used in this study for the purpose of analysis of risk factors for reduced bone mass, as the $\mathrm{Z}$ score eliminates the effects of age and sex by considering each patient's $\mathrm{BMD}$ in relation to the age and sex matched normal population.

The change in BMD $\left(\mathrm{g} \cdot \mathrm{cm}^{-2} \cdot \mathrm{y}^{-1}\right)$ is expressed as the absolute change per year (absolute BMD after 12 months-absolute $\mathrm{BMD}$ on entry) and as an annual percentage change:

protein, and energy were calculated from standard food composition tables. ${ }^{13}$

The body mass index (BMI) was calculated $\left(\mathrm{BMI}=\right.$ weight $/\left(\right.$ height $\left.\left.^{2}\right)\right)$. The presence or absence of other recognised risk factors for osteoporosis $^{14-16}$ (smoking, level of physical activity, immobilisation, presence of diabetes mellitus or thyroid disease, and drugs ingested) was determined using a standard questionnaire.

On entry to the study all patients had plasma calcium, phosphate, total alkaline phosphatase, 25 hydroxyvitamin $\mathrm{D}$, and intact parathyroid hormone ( $i \mathrm{PTH})$ as well as red cell folate and 24 hour urinary calcium measured.

Bone mineral density (BMD) was measured on entry to the study, and again at six and 12 months after entry to the study, at the lumbar spine (L1-4) and at the femoral neck using an Hologic QDR 1000 dual energy $x$ ray bone densitometer. The precision of the densitometer, expressed as the longitudinal coefficient of variation of daily lumbar spine 'phantom' measurements, was $0.5 \%$ over the period of the study.

BMD was expressed in absolute terms $\left(\mathrm{g} . \mathrm{cm}^{-2}\right)$ and the absolute BMD for each patient was then expressed as a $\mathrm{Z}$ score and a $\mathrm{T}$ score (defined below) when compared respectively with the mean BMD of an age and sex matched normal population and with the peak BMD (BMD at age 30 years) of a sex matched normal population. For both the $T$ score and the $\mathrm{Z}$ score the reference population data used were those provided by the American manufacturer and have been validated within our clinical measurement laboratory against the local population.

patient BMD-mean peak BMD of sex matched normals

SD of peak BMD of sex matched normals

patient $\mathrm{BMD}-$ mean $\mathrm{BMD}$ of age and sex matched normals

SD of BMD of age and sex matched normals

There is a close relationship between low BMD and fracture risk. ${ }^{16}$ Some authors consider a $T$ score $<-2$ as sufficient to diagnosis osteoporosis, whereas others define an

\section{Results}

Twenty one women (47\%) and five (50\%) men had a $\mathrm{T}$ score $<-2$ at either the lumbar spine or femoral neck, or at both sites (nine women and two men had $\mathrm{T}$ scores $<-2$ at both the lumbar spine and femoral neck). Eight of the patients (six women) with $\mathrm{T}$ score $<-2$ had a past history of important bone fracture. Ranked $\mathrm{T}$ scores at lumbar spine and femoral neck are shown in Figure 1.

Eleven $(20 \%)$ patients (nine women, two men) had a $Z$ score $<-2$ at either the lumbar spine or femoral neck, or both, four of whom (all female) had a $\mathrm{Z}$ score $<-2$ at both the lumbar spine and femoral neck. Thirteen $(24 \%)$ patients (10 women, three men) had $-2 \leqslant Z$ score $<-1$. Thirty one $(56 \%)$ patients ( 26 women, five men) had a $Z$ score $\geqslant-1$ at both the lumbar spine and femoral neck. Comparisons between these three groups of patients are shown in the Table. All patients with a $\mathrm{Z}$ score $<-2$ also had $\mathrm{T}$ score $<-2$.

There was a close correlation between the BMD (g. $\left.\mathrm{cm}^{-2}\right)$ at the lumbar spine and femoral neck (men: $\mathrm{r}=+0.782, \mathrm{p}<0.02$, 
Mean values of biochemical, dietary, and anthropometric results.

\begin{tabular}{|c|c|c|c|}
\hline & \multicolumn{3}{|l|}{$Z$ score range } \\
\hline & $\begin{array}{l}Z<-2 \\
(n=11)\end{array}$ & $\begin{array}{l}-2 \leqslant Z<-1 \\
(n=13)\end{array}$ & $\begin{array}{l}Z \geqslant-1 \\
(n=31)\end{array}$ \\
\hline $\begin{array}{l}\text { Women/men } \\
\text { Age }(\mathrm{y}) \\
\text { Years on gluten free diet } \\
\% \text { change in lumbar spine BMD/y } \\
\% \text { change in femoral neck BMD/y } \\
\text { Body mass index }\left(\mathrm{kg} \cdot \mathrm{m}^{-2}\right) \\
\text { Intake of calcium }(\mathrm{mg} / \mathrm{d})(\% \mathrm{RNI}) \\
\text { Intake of energy }(\mathrm{kJ} / \mathrm{d})(\% \mathrm{RNI}) \\
\text { Intake of protein }(\mathrm{g} / \mathrm{d})(\% \mathrm{RNI}) \\
\text { Serum calcium }(\mathrm{mmol} / \mathrm{h})(2 \cdot 20-2 \cdot 70) \\
\text { Serum phosphate }(\mathrm{mmol} / \mathrm{h})(0 \cdot 8-1 \cdot 5) \\
\text { Alkaline phosphatase }(\mathrm{IU} / 1)(21-92) \\
\text { Red cell folate }(\mu \mathrm{mol} / \mathrm{l})(0 \cdot 28-1 \cdot 36) \\
\text { PTH (pmol/ }(<4 \cdot 3)^{\star} \\
25 \text { hydroxyvitamin D }(\mathrm{nmol} / 1)(10-100) \\
24 \text { h urine calcium }(\mathrm{mmol} / 24 \mathrm{~h})(2 \cdot 5-7 \cdot 5) \\
\text { Haemoglobin }(\mathrm{g} / \mathrm{l}) \\
\text { Mean corpuscular volume (fl) }(75-95)\end{array}$ & $\begin{array}{c}9 / 2 \\
48 \cdot 7 \\
8 \cdot 9 \\
+0 \cdot 75 \\
+2 \cdot 08^{\star \star} \\
21 \cdot 3^{\star \star} \\
860(123)^{\star} \\
7879(94) \\
70(147) \\
2 \cdot 37 \\
1 \cdot 02 \\
77 \cdot 9 \\
0 \cdot 83 \\
2 \cdot 37 \\
55 \cdot 5 \\
4 \cdot 4 \\
137 \\
89 \cdot 9\end{array}$ & $\begin{array}{c}10 / 3 \\
51 \cdot 9 \\
4 \cdot 5 \\
+2 \cdot 40^{\star} \\
+3 \cdot 14^{\star \star} \\
23 \cdot 1 \\
1105(158) \\
9120(112) \\
79(169) \\
2 \cdot 25 \\
1 \cdot 04 \\
64 \cdot 6 \\
0 \cdot 83 \\
4 \cdot 12 \\
58 \cdot 3 \\
3 \cdot 2 \\
140 \\
89 \cdot 6\end{array}$ & $\begin{array}{l}26 / 5 \\
51 \cdot 6 \\
9 \cdot 2 \\
-0 \cdot 03 \\
-0 \cdot 31 \\
25 \cdot 2 \\
1054(151) \\
8115(98) \\
75(158) \\
2 \cdot 31 \\
1 \cdot 01 \\
70 \cdot 0 \\
0 \cdot 96 \\
3 \cdot 54 \\
59 \cdot 0 \\
3 \cdot 9 \\
135 \\
90 \cdot 1\end{array}$ \\
\hline
\end{tabular}

Significant difference between patients with reduced bone mineral density (BMD) $(Z<-2$ or $-2 \leqslant Z<-1)$ and patients with normal bone mineral density $(Z \geqslant-1)$ is denoted by an asterisk $(\star=p<0.05, \star \star=p<0.02, \star \star \star=p<0.01$, Wilcoxon rank sum test).

$\mathrm{RNI}=$ reference nutrient intake; $\mathrm{PTH}=$ parathyroid hormone.

women: $r=+0.704, p<0.001)$. The $\mathrm{BMD}$ at the lumbar spine (L1-4) in women is shown in Figure 2.

Serial BMD measurements showed an average annual change at the lumbar spine in men of +0.021 g. $\mathrm{cm}^{-2} \cdot \mathrm{y}^{-1} \quad(95 \% \quad \mathrm{CI}=-0.009$, $+0.055 \mathrm{~g} . \mathrm{cm}^{-2} \cdot \mathrm{y}^{-1}$ ) equivalent to $\mathrm{a}+2 \cdot 76 \%$ change, and in women of $+0.003(95 \%$ $\left.\mathrm{CI}=-0 \cdot 004,+0 \cdot 010 \mathrm{~g} \cdot \mathrm{cm}^{-2} \cdot \mathrm{y}^{-1}\right)$ equivalent to a $+0 \cdot 25 \%$ change. The average annual change at the femoral neck in men was +0.016 g. $\mathrm{cm}^{-2} \cdot \mathrm{y}^{-1} \quad(95 \% \quad \mathrm{CI}=-0.007, \quad+0.039$ g. $\mathrm{cm}^{-2} \cdot \mathrm{y}^{-1}$ ) equivalent to a $2.41 \%$ change, and in women of $+0.003(95 \% \mathrm{CI}=-0.005$, $+0.012 \mathrm{~g} . \mathrm{cm}^{-2} \cdot \mathrm{y}^{-1}$ ) equivalent to a $+0.66 \%$ change.

The change in $\mathrm{Z}$ score at the lumbar spine was $+0.26(95 \% \mathrm{CI}=-0.03,+0.56)$ in men and $+0.07(95 \% \mathrm{CI}=+0.01,+0.14, \mathrm{p}<0.025$ paired $t$ test) in women. The change in the $Z$ score at the femoral neck was $+0.25(95 \%$ $\mathrm{CI}=+0.04,+0.46, \mathrm{p}<0.05$ paired $t$ test $)$ in men and $+0.08(95 \% \mathrm{CI}=-0.02,+0.18)$ in women.

The average intakes of calcium, energy, and protein were above the reference nutrient intake for each nutrient (2 SDs above the

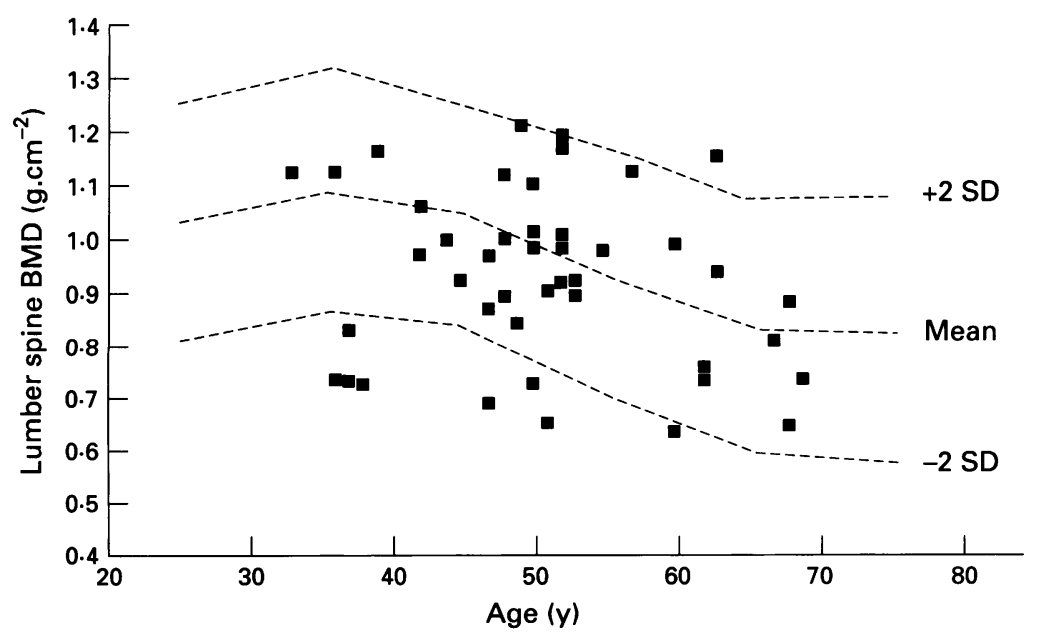

Figure 2: Lumbar spine bone mineral density (BMD) in 45 women with coeliac disease. Mean (2SD) are derived from the age and sex matched normal population. intake for a nutrient that would be adequate for $50 \%$ of the normal population). The United Kingdom reference nutrient intake (RNI) for calcium is $700 \mathrm{mg} /$ day for adults. ${ }^{21}$

The mean plasma concentrations of calcium, phosphate, total alkaline phosphatase, 25 hydroxyvitamin D, red cell folate, and 24 hour urine calcium were in the normal range (Table), however, some patients had a minor reduction of calcium or phosphate, or a slight increase in total alkaline phosphatase or $\imath \mathrm{PTH}$. No patient had a subnormal 25 hydroxyvitamin $\mathrm{D}$ value, but levels near the lower limit of the normal range were detected in a few. Bone biopsies showed severe osteoporosis, with marked trabecular thinning, but there was no increase in osteoid thickness or any other histological evidence of osteomalacia in either of the patients who had this investigation.

Compared with patients with a $\mathrm{Z}$ score $\geqslant-1$ at both lumbar spine and femoral neck (Table), patients with $\mathrm{Z}$ score $<-2$ at one or both sites had significantly lower average daily calcium intake ( $860 \mathrm{mg} / \mathrm{d}$ compared with 1054 $\mathrm{mg} / \mathrm{d}, \mathrm{p}<0.05)$ and a lower BMI $\left(21.3 \mathrm{~kg} . \mathrm{m}^{-2}\right.$ compared with $\left.25 \cdot 2 \mathrm{~kg} \cdot \mathrm{m}^{-2}, \mathrm{p}<0 \cdot 02\right)$. There was no significant difference $(p>0 \cdot 10)$ between these groups in the length of time on a gluten free diet, age at diagnosis of coeliac disease, any of the blood or urine biochemical indices, or of other risk factors for osteoporosis (smoking, level of physical activity, use of glucocorticoids, age at menarche in women).

There was no significant difference in $\mathrm{Z}$ scores in premenopausal, perimenopausal, or postmenopausal women at either the lumbar spine or femoral neck. In postmenopausal females, however, the age at menopause was significantly correlated with the lumbar spine $\mathrm{Z}$ score $(\mathrm{r}=+0.681, \mathrm{p}<0.01)$ and with the femoral neck $Z$ score $(r=+0.632, p<0.01$, Fig $3)$. Patients with a history of bone fracture had no significant difference in $\mathrm{Z}$ score when compared with patients with no history of fracture.

There was no significant correlation between the duration of the GFD and the femoral or lumbar $Z$ score, but there was a negative correlation between the annual percentage change in the $\mathrm{BMD}$ at the lumbar spine (women: $\mathrm{r}=-0.405, \mathrm{p}<0.01$, men: $r=-0.709, p<0.05$, Fig 4). Many of the most recently diagnosed patients showed a significant improvement in BMD over the 12 months of the study. The four osteoporotic women who lost bone more rapidly than $-2 \%$ per annum at the lumbar spine had all undergone the menopause at age 40 years or less.

\section{Discussion}

Bone mass increases throughout childhood and adolescence ${ }^{22} 23$ to the peak bone mass at about the third decade with a slow decline thereafter in men and premenopausal women $^{24}$ and a rapid loss of bone mass in women in the early postmenopausal years. ${ }^{25}$ Peak bone mass and the subsequent decline in bone mass are both determined by genetic and acquired factors. Acquired or environmental factors that may contribute to low bone mass 


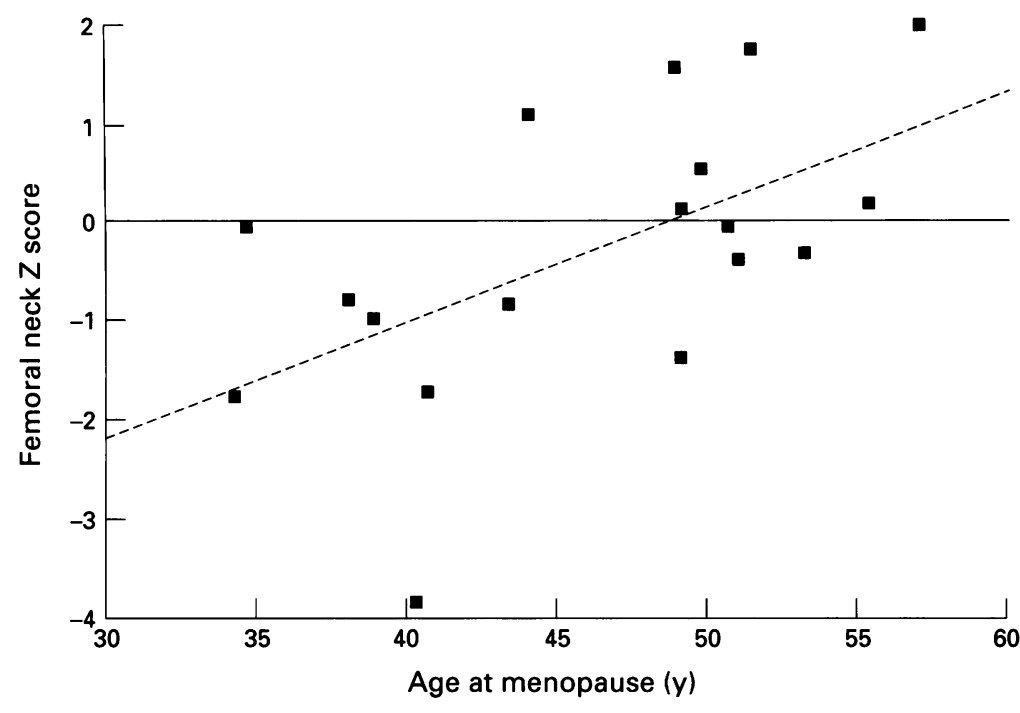

Figure 3: Femoral neck $Z$ score $\mathrm{v}$ age at menopause in postmenopausal women. There is a significant correlation between bone mineral density and age at menopause ( $n=18$, $r=0.632, p<0 \cdot 01$, Spearman's rank correlation).

and fracture risk include dietary calcium intake, the level of physical activity, and in women, oestrogen deprivation. ${ }^{25}$

In coeliac disease the villous atrophy and malabsorption are thought to occur at the time of first exposure to gluten - that is, at weaning. Patients in this study were all diagnosed in adult life, after the age at which the maximum rate of gain of bone mass occurs, ${ }^{22}$ and a possible explanation for the low BMD seen is that they failed to reach an optimal peak bone mass in early adult life. ${ }^{9}$ Forty seven per cent of patients in this study had osteoporosis defined as a bone mineral density $2 \mathrm{SD}$ or more below the mean sex matched peak bone mass.

Reduced bone mineral density occurred in all age ranges, in both sexes, and in many cases was quite profound. Twenty four per cent of patients had $-2<Z$ score $<-1$, and therefore at least a twofold increase in lifetime fracture risk, and $20 \%$ of patients had $\mathrm{Z}$ score $<-2$, and therefore at least a fivefold increase in lifetime fracture risk.

Postmenopausal patients with coeliac disease who had an early menopause were

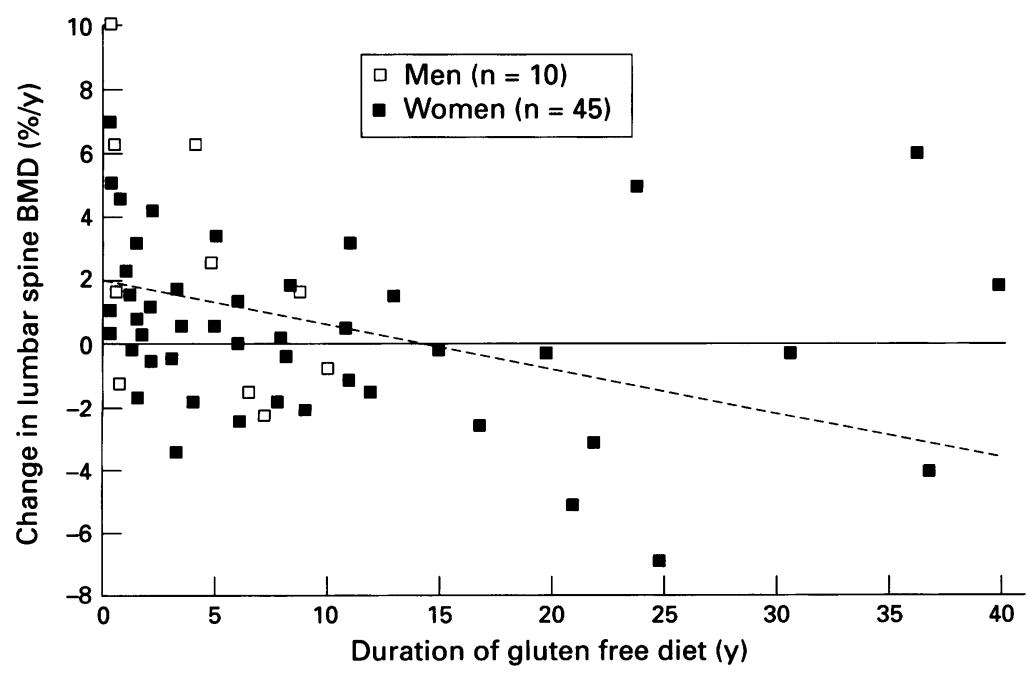

Figure 4: There is a negative correlation between the rate of change of bone mineral density (BMD) (\% change per year) in relation to duration on gluten free diet ( $n=55$, $r=-0 \cdot 429, p<0 \cdot 01$, Spearman's rank correlation). particularly susceptible to low bone density, and to a rapid loss of bone mass $(>-2 \%$ /year) whereas women with an onset of menopause after the age of 50 years seemed to be relatively protected from low bone density, and did not suffer rapid bone loss. It is clear that the protective effect of oestrogens on bone mass remains important in women with coeliac disease.

There was a predominance of females in the study $(4 \cdot 5: 1)$ which is higher than that reported for coeliac disease in general (1:1 to $2: 1) .{ }^{27}$ This bias in the study population is probably explained by the demanding nature of the study which discouraged men in full time employment from taking part. However, the magnitude of the abnormalities shown seems to be of the same order in men and women. There was a high proportion of perimenopausal and postmenopausal women, but it is unlikely that all of the reduction in BMD is due to menopausal loss. Premenopausal women had a lower (not significant, $\mathrm{p}>0 \cdot 10$ ) absolute BMD than menopausal women, and some of the patients with the lowest $\mathrm{Z}$ scores were premenopausal.

In some individuals, calcium intake was marginal. Bread and cereals contribute approximately $25 \%$ of dietary calcium, ${ }^{28}$ and unless the individual has an adequate intake of dairy products, a gluten free diet may not provide adequate dietary calcium. In addition, the United Kingdom recommended nutrient intakes for calcium may not be adequate for adults with treated coeliac disease as there is evidence for continued malabsorption of calcium despite a gluten free diet. ${ }^{29}$ The correlation of bone mass with dietary calcium intake demonstrated in this study provides evidence to support a recommendation to increase calcium intakes in patients with coeliac disease to levels recommended for adults by the American National Institutes of Health $^{30}(1000 \mathrm{mg} / \mathrm{d}$ for premenopausal women and $1500 \mathrm{mg} / \mathrm{d}$ for post menopausal women not treated with oestrogen).

There were no biochemical parameters which predicted osteoporosis in this study, but the clear association with BMI is helpful, and is consistent with the recognised association in the general population. 141531

We have shown an overall increase in the BMD Z score over the 12 months of the study at the lumbar spine in women and femoral neck in men which is surprising and requires explanation. The largest gains in $\mathrm{Z}$ scores and absolute BMD were detected in the most recently diagnosed patients suggesting that there is a reversible component to the osteopaenia present at the time of diagnosis of coeliac disease, and that this can be improved by treatment with a gluten free diet. The rapid loss of bone in women who had the menopause at age less than 45 years emphasises the continuing skeletal demineralisation and need for active treatment in this group.

Screening for osteoporosis by measuring bone mineral density in adult coeliac disease seems to be worthwhile with a high yield, many patients having reduced bone mineral density. 
This has therapeutic potential, and having identified at risk individuals the need for adherence to gluten free diet can be emphasised and advice regarding treatment can be offered, which may include increasing dietary calcium intake or considering hormone replacement treatment in postmenopausal women, in particular those with an early menopause.

This work was supported by a grant from the Coeliac Trust.

1 Juergens JL, Scholz DA, Wollager EE. Severe osteomalacia associated with occult steatorrhoea due to non trop cal sprue. Report of 5 cases. Arch Intern Med 1956; 98. 774-82.

2 Hajjar ET, Vincenti F, Salti CS. Gluten induced enteropathy: osteomalacia as a principal manifestation. Arch Intern Med 1979; 131: 565-6.

3 De Boer WA, Tytgat GN. A patient with osteomalacia as a single presenting symptom of gluten sensitive enterosingle presenting symptom of gluten

4 Melvin K, Hepner G, Bordier P, Neale G, Joplin G. Calcium metabolism and bone pathology in adult coeliac disease. $Q \mathcal{F}$ Med 1970; 39: 82-113.

5 Bode S, Hassager C, Gudmand-Hoyer E, Christiansen C. Body composition and calcium metabolism in adult treated coeliac disease. Gut 1991; 32: 1342-5.

6 Lindh E, Ljunghall S, Larsson K, Lavo B. Screening for antibodies against gliadin in patients with osteoporosis. f Intern Med 1992; 231: 403-6.

7 Logan RFA, Tucker G, Rifkind EA, Heading RC, Ferguson A. Changes in clinical features of coeliac disease in adults in Edinburgh and the Lothians 1960-1979. BMF 1983; 286: Edinb.

8 Corazza GR, Frisoni M, Treggiari EA, Valentini RA, Filipponi C, Volta U, et al. Subclinical coeliac sprue: Increasing occurrence and clues to its diagnosis. $\mathscr{f}$ Clin Gastroenterol 1993; 16: 16-21.

9 Molteni N, Caraceni MP, Bardella MT, Ortolani S, Gandolini GG, Bianchi P. Bone mineral density in adult coeliac patients and the effect of a gluten free diet from childhood. Am $\mathcal{F}$ Gastroenterol 1990; 85: 51-3.

10 Caraceni MP, Molteni N, Bardella MT, Ortolani S, Nogara A, Bianchi PA. Bone and mineral metabolism in adult coeliac disease. Am $\mathcal{f}$ Gastroenterol 1988; 83: 274-7.

11 Trier JS. Celiac sprue. In: Sleisenger MH, Fordtran JF, eds. Gastrointestinal diseases. Pathophysiology, diagnosis,
management. Philadelphia: WB Saunders Company, 1993: manage 1078 .

12 Dietary Assessment Methodology. In: Thomas B. Manual of dietetic practice. Oxford: Blackwell Scientific Publications, 1988: 15-28.

13 Holland B, Welch AA, Unwin ID, Buss DH, Paul AA, Southgate DAT. McCance and Widdowson's The composition of foods. London: The Royal Society of Chemistry and Ministry of Agriculture, Fisheries and Food, 1991.
14 Slemenda CW, Hui SL, Longcope C, Wellman H, Johnston CC Jr. Predictors of bone mass in perimenopausal women. A prospective study of clinical data using photon women. A prospective study of clinical data using phot

15 Falch JA, Sandvik L, Van Beresteijn ECH. Development and evaluation of an index to predict early postmenopausal bone loss. Bone 1992; 13: 337-41.

16 Reginster JY, Denis D, Deroisy R, Albert A, Sarlet N, Collette J, et al. Dual photon absorptiometry of lumbar spine in west European (Belgian) postmenopausa females: normal range and fracture threshold. Clin Rheumatol 1990; 9: 220-4.

17 Nordin BEC. The definition and diagnosis of osteoporosis [Editorial]. Calcified Tissue International 1987; 40: 57-8.

18 Smith $R$. Disorders of the skeleton. In: Weatherall DJ, Ledringham JGG, Warrell DIA, eds. Oxford textbook of medicine. Oxford: Oxford University Press, 1987: medicine.

19 Cummings SR, Black DM, Nevitt MC, Browner W, Cauley $\mathrm{J}$, Ensrud $\mathrm{K}$, et al. Bone density at various sites for prediction of hip fractures. The study of osteoporotic fractures research group. Lancet 1993; 341: 72-5.

20 Boyce BF. Uses and limitations of bone biopsy in management of metabolic bone disease. Ballières Clin Endocrinol Metab 1988; 2: 31-57.

21 Dietary reference values for food, energy and nutrients for the UK. London: HMSO, 1991. Report on health and social subjects No 41 .

22 Theintz G, Buchs B, Rizzoli R, Slosman D, Clavien H, Sizonenko PC, Bonjour JP. Longitudinal monitoring of bone mass accumulation in healthy adolescents: evidence for a marked reduction after 16 years of age at the levels of the lumbar spine and femoral neck in female subjects. $f$ Clin Endocrinol Metab 1992; 75: 1060-5.

23 Rico H, Revilla M, Hernandez ER, Villa LF, Lopez-Alfonso A. Total and regional bone mineral content in norma premenopausal women. Clin Rheumatol $1991 ; 10: 423-5$.

24 Kroger H, Heikkinen J, Laitinen K, Kotaniemi A. Dual energy $\mathrm{X}$ ray absorptiometry in normal women: A cross sectional study of 717 Finnish volunteers. Osteoporosis sectional study of 717 Finn
International 1992; 2: 135-40.

25 Uebelhart D, Schlemmer A, Johansen JS, Gineyts E, Christiansen C, Delmas P. Effect of menopause and hormone replacement on the urinary excretion of pyridinium cross links. F Clin Endocrinol Metab 1991; 72 : 367-73.

26 Toss G. Effect of calcium intake vs other life style factors on bone mass. F Intern Med 1992; 231: 181-6.

27 Howdle PD, Losowsky M. Coeliac disease in adults. In Marsh MN, ed. Coeliac disease. Oxford: Blackwell Scientific Publications, 1992: 49-80.

28 Gregory J, Foster $\mathrm{K}$, Tyler H, Wiseman $M$. The dietary and nutritional survey of British adults. London: HMSO, 1990: 160.

29 Milsom S, Ibbertson K, Hannan S, Shaw D, Pybus J. Simple test of calcium absorption measured by stable strontium. $B M \mathcal{F} 1987$; 295: 231-4.

30 National Institutes of Health Consensus Conference Statement. Osteoporosis. fAMA 1984; 252: 799-802.

31 Felson DT, Zhang Y, Hannan MT, Anderson JJ. Effects of weight and body mass index on bone mineral density in men and women: The Framingham study. $f$ Bone Miner Res 1993; 8: 567-73. 